\title{
Concordance between Microorganisms Isolated from Subglottic Secretions and Bronchoalveolar Lavage Fluid in Patients with Ventilator Associated Pneumonia in Intensive Care Unit
}

\author{
Kapil Alias Mohit Chilana, Latha Sarma, Nandan Putti, Sambit Sahu, Suchira Chillana ${ }^{1}$ \\ Department of Pulmonology, Krishna Institute of Medical Sciences, Secunderabad, Telangana, 'Department of Microbiology, Government Medical College, \\ Amritsar, Punjab, India
}

\section{Abstract}

Introduction: Nosocomial pneumonia is a common complication in critically ill patients. Mechanical ventilation has been consistently identified as the greatest risk factor for the development of nosocomial pneumonia. Aims: The purpose of the current study is to find the concordance between microorganisms cultured from subglottic secretions and bronchoalveolar lavage fluid (BALF) and to assess the effectiveness of subglottic suctioning for prevention of ventilator-associated pneumonia (VAP). Patients and Methods: This was a prospective, interventional, cohort study. Patients between 15 and 85 years who developed VAP after receiving mechanical ventilation were enrolled in the study. They were randomly divided into two groups: Group No Subglottic Secretion Drainage (NSSD) and Group Continuous Subglottic Secretion Drainage (CSSD). Results: The mean age of the patients was $56 \pm 13$ years. Fifty-eight percent were males and $42 \%$ were females. The incidence of VAP among NSSD group was $41.7 \%$ and in CSSD group was $25 \%$. The coefficient of correlation was calculated for the microorganisms cultured in subglottic and BALF using Pearson's correlation. The correlation coefficient was 0.78 for the entire population $(P=0.01)$. In the NSSD group, it was $0.82(P=0.01)$, and in the CSSD group, it was $0.76(P=0.01)$. The mean Intensive Care Unit (ICU) stay is maximum in NSSD group (12.9 \pm 1.84 days) compared to CSSD group ( $9.2 \pm 1.17$ days). Conclusion: The concordance of organism grown in subglottic secretions and BALF culture is higher in NSSD group as compared to CSSD group. CSSD is an effective means of reducing the number of ventilator days and ICU stay.

Keywords: Bronchoalveolar lavage fluid, continuous suctioning, intermittent suctioning, subglottic secretions, ventilator-associated pneumonia

\section{INTRODUCTION}

Nosocomial pneumonia is a common complication in critically ill patients. It is also the most common nosocomial infection with an overall prevalence of $10 \% \cdot{ }^{[1]}$ The greatest risk factor identified for the development of nosocomial pneumonia is mechanical ventilation. ${ }^{[2-6]}$ In Intensive Care Unit (ICU) patients, $80 \%-90 \%$ of cases of nosocomial pneumonia are ventilator-associated pneumonia (VAP).$^{[4,7,8]}$ The risk of VAP is highest in the first few days of intubation, with a daily hazard rate of approximately $3 \%$ at day 5 of intubation, decreasing to $1 \%$ day $9 .{ }^{[9,10]}$

Endotracheal intubation predisposes to nosocomial pneumonia through several possible mechanisms:

a. Aspiration of oropharyngeal secretions during tracheal intubation ${ }^{[11,12]}$

\begin{tabular}{|l|l|}
\hline \multicolumn{2}{|c|}{ Access this article online } \\
\hline Quick Response Code: & Website: \\
\hline & www.ijrconline.org \\
\hline & \\
\hline
\end{tabular}

b. Loss of mucosal integrity due to intubation-related trauma

c. Reduced mucociliary clearance of secretions

d. Microaspiration of secretions around the inflated endotracheal tube (ETT) cuff

e. Biofilm formation and bacterial colonization inside the ETT lumen.

Thus, measures to prevent VAP include preventing aspiration of secretions, minimize trauma, reduce the duration of invasive

Address for correspondence: Dr. Kapil Alias Mohit Chilana, Krishna Institute of Medical Sciences, Secunderabad, Telangana, India. E-mail: drkapchillu@gmail.com

This is an open access article distributed under the terms of the Creative Commons Attribution-NonCommercial-ShareAlike 3.0 License, which allows others to remix, tweak, and build upon the work non-commercially, as long as the author is credited and the new creations are licensed under the identical terms.

For reprints contact: reprints@medknow.com

How to cite this article: Chilana KA, Sarma L, Putti N, Sahu S, Chillana S. Concordance between microorganisms isolated from subglottic secretions and bronchoalveolar lavage fluid in patients with ventilator associated pneumonia in Intensive Care Unit. Indian J Respir Care 2017;6:824-7. 
mechanical ventilation, reducing bacterial colonization of aerodigestive tract, minimizing secretions above cuff with the use cuffed ETT with inline or subglottic suctioning, preventing contamination of lower airway, and preventing exposure to contaminated equipment. The purpose of the current study was to assess the effectiveness of subglottic suctioning for prevention of VAP.

\section{Patients and Methods}

This was a prospective, interventional, cross-sectional study. Patients in the age group between 15 and 85 years admitted to the ICU from October 2014 to June 2016 who developed VAP after receiving mechanical ventilation (fulfilling criteria of VAP definition as per Centre for Disease Control and Prevention) were enrolled in the study. The study was started after the approval of Ethics Committee. The study population was from both rural and urban areas near the hospital and was from all socioeconomic classes.

The patients were randomly divided into two groups: Group No subglottic secretion drainage (NSSD) where they were intubated with ETT of Portex ${ }^{\circledR}$ brand without provision of suction above cuff and Group Continuous subglottic secretion drainage (CSSD) where ETT of Portex ${ }^{\circledR}$ brand with provision of suction above cuff was used.

Patients with acute myocardial infarction or unstable angina, cardiac arrhythmias, refractory hypoxemia, pulmonary hypertension, lung abscess, hemodynamically unstable patients, requirement of high levels of positive end-expiratory pressure, cultures showing growth of fungus, and patients referred from another hospital diagnosed as VAP were excluded from the study.

A total of 220 critically ill patients were enrolled in this period, 120 patients in NSSD group and 100 in the CSSD group. Fifty patients in each group developed VAP on follow-up. Thus, the total population in this study was 100 .

The ETT cuff pressure was maintained in a range of $18-24 \mathrm{cmH}_{2} \mathrm{O}$ and was regularly monitored in both groups. Continuous subglottic suctioning was accomplished with a special ETT with a suction port in the dorsal lumen that resides just above the inflated balloon. This permits aspiration of secretions in the subglottic space, ${ }^{[13,14]}$ thus preventing pooling of these secretions above inflated cuff which could lead to aspiration.

Subglottic secretions were collected under strict aseptic precautions into mucous extractor using a suction pressure of $20-30 \mathrm{cmH}_{2} \mathrm{O}$ and were immediately transported to the laboratory for microbiological examination (for aerobic bacterial culture).

Bronchoalveolar lavage fluid (BALF) specimens were collected under strict aseptic precautions using Olympus BF 180 series fiber-optic bronchoscope. A volume of 50-200 $\mathrm{mL}$ of sterile saline was infused into the distal bronchoalveolar tree. Subsequently, suctioning was done and immediately transported to the laboratory for microbiological examination (for aerobic bacterial culture). Both the subglottic and BALF samples were collected at the same time and were subjected to microbiology laboratory within half an hour for culture and identification of microorganisms. The samples were inoculated on blood agar and MacConkey's agar and incubated for a period of 48-72 $\mathrm{h}$ for the growth of the bacteria. The colony morphology was studied. Preliminary identification tests such as Gram stain, motility, catalase, and oxidase test were performed. The samples were then subjected for aerobic bacterial cultures. Identification of the bacteria was done by the card (Gram-positive and Gram-negative) of VITEK-2 compact (vio Merieux).

Data of continuous variables were reported as means \pm standard deviation whereas categorical data were expressed as percentages or frequency tables. Correlation analysis was done to evaluate the association between various measured variables. Student's $t$-test was used to compare the incidence of VAP in both groups. Odds ratio was calculated using Chi-square test, from which relative risk reduction was estimated. A value of $P<0.05$ was considered to be statistically significant. All statistical analyses were done using SPSS version 17.0, IBM Computers (SPSS Inc. Released 2008. SPSS Statistics for Windows, Version 17.0. Chicago).

\section{RESULTS}

The mean age of the patients was $56 \pm 13$ years. Fifty-eight patients were males. The incidence of VAP among NSSD group was $41.7 \%$ and in CSSD group was $25 \%$ [Table 1]. The odds ratio was 0.467 (confidence interval: $0.28,0.75$ ) with a relative risk reduction of 0.39 .

Among the various comorbidities, hypertension $(28.57 \%)$ was the most common and seizure disorder (1.68\%), the least. Other comorbidities are mentioned in Table 2. Respiratory failure (type 1 and type 2) and airway protection were the two reasons for intubation, Type 2 respiratory failure was seen in $90 \%$ of patients in the NSSD group and $82 \%$ of patients in CSSD group. Majority of the patients were suffering from chronic obstructive pulmonary disease (COPD) and presented with acute exacerbation of underlying COPD.

The most common microorganisms among the patients who were diagnosed with early onset VAP (EOVAP) was Klebsiella pneumoniae (43\%). Among the patients with late onset VAP (LOVAP), Acinetobacter baumannii was the most common (30\%). The most common microorganism in the NSSD group was $K$. pneumoniae (44\%), and in CSSD group, A. baumannii (32\%). The prevalence of various other microorganisms as a causative agent in this study population is depicted in Table 3. The coefficient of correlation for the microorganisms cultured from subglottic and BALF in each group was calculated using Pearson's correlation. In the total study population, the correlation coefficient was 
Chilana, et al.: Concordance between micro-organisms isolated from subglottic secretions and BAL fluid

$0.78(P=0.01)$. In the NSSD group, the correlation coefficient was $0.82(P=0.01)$. In the CSSD group, correlation coefficient was $0.76(P=0.01)$.

The average number of days of mechanical ventilation at the time of VAP diagnosis was more in CSSD group with $5.82 \pm 0.69$ days, whereas, in NSSD group, VAP was diagnosed within $3.62 \pm 0.67$ days $(P=0.0001)$. The average duration of mechanical ventilator support in CSSD group was $7.8 \pm 1.03$ days compared to $10.5 \pm 1.18$ days in the NSSD group $(P=0.0001)$. The mean ICU stay was also higher in the NSSD group $(12.9 \pm 1.84$ days $)$ compared to CSSD group $(9.2 \pm 1.17$ days $)(P=0.0001)$ [Table 4 ]

\section{Discussion}

VAP is a prevalent and costly nosocomial infection related to instrumentation of the airway with an ETT, enabling microaspiration of contaminated secretions.

In our study, the incidence of VAP in NSSD group was $41.66 \%$ and in the CSSD group was $25 \%$. Compared to study done by Ranjan et al., overall incidence of VAP was $57.14 \%{ }^{[15]}$ The lower incidence in the present study may be due to differences in study population, definition of VAP itself (clinically vs. microbiologically oriented) and possibly, to the use of preventive strategies.

The 39\% relative risk reduction in the incidence of VAP was significant with the adoption of subglottic suction ETTs. The proportion of EOVAP (47\%) and LOVAP (53\%) was similar to that in the study by Golia et al. ${ }^{[16]}$ In their study, $44.23 \%$ had EOVAP and $55.77 \%$, LOVAP.

Among other factors, age is an important factor. As age increases, the immune response and mucociliary clearance decrease increasing the susceptibility for VAP development. Bonten et al. found that age $>60$ years was a nonmodifiable risk factor with an odds ratio of 5.1. ${ }^{[17]}$ In our study, the mean age group was $56 \pm 13$ years. VAP also has a male preponderance as seen by Jaimes et al. ${ }^{[18]}(58 \%)$ and Huang et al. ${ }^{[19]}(67 \%)$ of VAP patients.

The incidence of comorbidities is similar to that seen in the study by Huang et al. with hypertension being the most common $(28.57 \%)$ followed by diabetes mellitus $(20.16 \%)$ and chronic kidney disease $7.56 \% .^{[20]}$

The onset of VAP was delayed in the CSSD group by $5.82 \pm 0.69$ days versus NSSD group by $3.62 \pm 0.67$ days. These findings are similar to that of Yang et al. ${ }^{[20]}$ Patients with continuous aspiration of subglottic secretions had delayed onset of VAP ( $7.3 \pm 4.2$ days $)$ as compared to No aspiration of subglottic secretions $(5.1 \pm 3.0$ days $)(P=0.100)$.

In another randomized study that included 714 patients undergoing cardiac surgery, subglottic secretions removal demonstrated a significant reduction in the incidence of VAP, ICU length of stay, antibiotic use, and overall mortality. ${ }^{[11]}$ In our study, the length of ICU stay in CSSD

\begin{tabular}{|c|c|c|c|}
\hline \multicolumn{4}{|c|}{ Table 1: Incidence of ventilator-associated pneumonia $n$ (\%) } \\
\hline & No VAP & VAP & $\boldsymbol{P}$ \\
\hline Group NSSD & $70(58.3)$ & $50(41.7)$ & 0.0027 \\
\hline Group CSSD & $150(75)$ & $50(25)$ & \\
\hline Total & 220 & 100 & \\
\hline \multicolumn{4}{|c|}{$\begin{array}{l}\text { Chi-square test. VAP: Ventilator-associated pneumonia, } \\
\text { NSSD: No-subglottic secretion drainage, CSSD: Continuous subglottic } \\
\text { secretion drainage }\end{array}$} \\
\hline \multicolumn{4}{|c|}{$\begin{array}{l}\text { Table 2: Underlying comorbidities of patients in } \\
\text { no-subglottic secretion drainage and continuous subglottic } \\
\text { secretion drainage group }\end{array}$} \\
\hline Diagnosis & & $\begin{array}{c}\text { Group NSSD, } \\
n(\%)\end{array}$ & $\begin{array}{c}\text { Group CSSD, } \\
n(\%)\end{array}$ \\
\hline \multicolumn{2}{|c|}{ Acute exacerbation of COPD } & $18(36.73)$ & $16(37.20)$ \\
\hline \multicolumn{2}{|c|}{$\begin{array}{l}\text { Acute exacerbation of bronchial } \\
\text { asthma }\end{array}$} & $15(30.61)$ & $13(30.23)$ \\
\hline \multicolumn{2}{|c|}{ Obstructive sleep apnea } & $10(20.40)$ & $9(20.93)$ \\
\hline \multicolumn{2}{|c|}{ Systemic lupus erythematosus } & $3(6.12)$ & $3(6.97)$ \\
\hline \multicolumn{2}{|c|}{ Coronary artery disease } & $2(4.08)$ & $1(2.32)$ \\
\hline \multicolumn{2}{|c|}{$\begin{array}{l}\text { Interstitial lung } \\
\text { disease (infective exacerbation) }\end{array}$} & $1(2.04)$ & $0(0)$ \\
\hline \multicolumn{2}{|c|}{ Tubercular lymphadenitis } & $0(0)$ & $1(2.32)$ \\
\hline
\end{tabular}

COPD: Chronic obstructive pulmonary disease, NSSD: No-subglottic secretion drainage, CSSD: Continuous subglottic secretion drainage

\begin{tabular}{|c|c|c|c|c|}
\hline \multirow[t]{2}{*}{ Bacteria cultured } & \multicolumn{2}{|c|}{ NSSD (\%) } & \multicolumn{2}{|c|}{ CSSD (\%) } \\
\hline & EOVAP & LOVAP & EOVAP & LOVAP \\
\hline Acinetobacter baumannii & $16(34)$ & $2(66.7)$ & 0 & $16(32)$ \\
\hline Escherichia coli & $4(8.5)$ & 0 & 0 & $5(10)$ \\
\hline Klebsiella pneumoniae & $20(42.5)$ & 0 & 0 & $12(24)$ \\
\hline Proteus mirabilis & 0 & 0 & 0 & $3(6)$ \\
\hline Pseudomonas aeruginosa & $7(14.9)$ & $1(33.3)$ & 0 & $12(24)$ \\
\hline Serratia marcescens & 0 & 0 & 0 & $2(4)$ \\
\hline Total & $47(100)$ & $3(100)$ & 0 & $50(100)$ \\
\hline
\end{tabular}

NSSD: No-subglottic secretion drainage, CSSD: Continuous subglottic secretion drainage, VAP: Ventilator-associated pneumonia, EOVAP: Early-onset VAP, LOVAP: Late onset VAP

Table 4: The number of ventilated days at the diagnosis of ventilator-associated pneumonia, total number of ventilator days, duration of mechanical ventilation, and duration of Intensive Care Unit stay (days)

\begin{tabular}{lccc}
\hline Parameter & $\begin{array}{c}\text { Group NSSD } \\
(\boldsymbol{n}=\mathbf{5 0})\end{array}$ & $\begin{array}{c}\text { Group CSSD } \\
(\boldsymbol{n}=\mathbf{5 0})\end{array}$ & $\boldsymbol{P}$ \\
\hline $\begin{array}{l}\text { Days of ventilation at the } \\
\text { time of VAP diagnosis }\end{array}$ & $3.62 \pm 0.67$ & $5.82 \pm 0.69$ & 0.0001 \\
$\begin{array}{l}\text { Days of mechanical } \\
\text { ventilation }\end{array}$ & $10.5 \pm 1.18$ & $7.8 \pm 1.03$ & 0.0001 \\
\begin{tabular}{l} 
Duration of ICU stay \\
\hline
\end{tabular} & $12.9 \pm 1.84$ & $9.2 \pm 1.17$ & 0.0001 \\
\hline
\end{tabular}

Data presented in mean \pm SD. SD: Standard deviation, ICU: Intensive Care Unit, VAP: Ventilator-associated pneumonia, NSSD: No-subglottic secretion drainage, CSSD: Continuous subglottic secretion drainage 
group was $9.2 \pm 1.17$ days compared to $12.9 \pm 1.84$ days in NSSD group.

In the study conducted by Ahmed A Alsaddique, the use of continuous subglottic suction was beneficial even in the case of established VAP. It prevents further soiling of the airways, hastens recovery, and shortens the ICU stay. They suggested that subglottic suction is instituted early in case of prolonged mechanical ventilation to prevent VAP. ${ }^{[21]}$

The most common microorganism cultured from BALF was K. pneumoniae followed by A. baumannii in the current study. Ranjan et al. identified A. baumannii followed by Pseudomonas aeruginosa were the most common microorganisms in their study. ${ }^{[15]}$ In our study, the microorganisms cultured in EOVAP was $K$. pneumoniae most common followed by $A$. baumannii in EOVAP, but it was reversed in LOVAP. Golia et al. isolated P. aeruginosa, Escherichia coli, and A. baumannii in EOVAP and LOVAP. ${ }^{[16]}$

Colonization of the oropharynx is an independent predictor for tracheobronchial colonization. Aspiration of these bacteria-containing secretions is the main mechanism of acquiring VAP in mechanically ventilated patients. ${ }^{[22]}$ In our study, the concordance between microorganisms isolated from subglottic and BALF cultures showed that the microorganism present in subglottic secretions might have been microaspirated into lower respiratory tract leading to VAP.

The coefficient of correlation of bacteria cultured from subglottic and BALF of NSSD group was $0.82(P=0.01)$ and that of CSSD group was $0.76(P=0.01)$. This shows that concordance of bacteria in subglottic and BALF is more in NSSD group when compared CSSD group.

\section{ConcLusion}

The use of continuous subglottic suction reduces the incidence of VAP and the number of days of mechanical ventilation and duration of ICU stay. A greater concordance of organisms grown in subglottic and BALF cultures, when subglottic suction is not used, suggests a reduction of aspiration of subglottic secretions as a factor contributing to VAP when ETTs with subglottic suction are used.

\section{Financial support and sponsorship}

Nil.

\section{Conflicts of interest}

There are no conflicts of interest.

\section{RefEREnCES}

1. Vincent JL, Bihari DJ, Suter PM, Bruining HA, White J, Nicolas-Chanoin MH, et al. The prevalence of nosocomial infection in Intensive Care Units in Europe. Results of the European Prevalence of Infection in Intensive Care (EPIC) Study. EPIC International Advisory Committee. JAMA 1995;274:639-44.

2. Celis R, Torres A, Gatell JM, Almela M, Rodríguez-Roisin R, Agustí-Vidal A. Nosocomial pneumonia. A multivariate analysis of risk and prognosis. Chest 1988;93:318-24.
3. Langer M, Cigada M, Mandelli M, Mosconi P, Tognoni G. Early onset pneumonia: A multicenter study in Intensive Care Units. Intensive Care Med 1987;13:342-6.

4. Chevret S, Hemmer M, Carlet J, Langer M. Incidence and risk factors of pneumonia acquired in intensive care units. Results from a multicenter prospective study on 996 patients. European Cooperative Group on Nosocomial Pneumonia. Intensive Care Med 1993;19:256-64.

5. Cross AS, Roup B. Role of respiratory assistance devices in endemic nosocomial pneumonia. Am J Med 1981;70:681-5.

6. Cunnion KM, Weber DJ, Broadhead WE, Hanson LC, Pieper CF, Rutala WA. Risk factors for nosocomial pneumonia: Comparing adult critical-care populations. Am J Respir Crit Care Med 1996;153:158-62.

7. Richards MJ, Edwards JR, Culver DH, Gaynes RP. Nosocomial infections in medical Intensive Care Units in the United States. National Nosocomial Infections Surveillance System. Crit Care Med 1999;27:887-92.

8. Richards MJ, Edwards JR, Culver DH, Gaynes RP. Nosocomial infections in combined medical-surgical Intensive Care Units in the United States. Infect Control Hosp Epidemiol 2000;21:510-5.

9. Eggimann P, Hugonnet S, Sax H, Touveneau S, Chevrolet JC, Pittet D. Ventilator-associated pneumonia: Caveats for benchmarking. Intensive Care Med 2003;29:2086-9.

10. Cook D, Guyatt G, Marshall J, Leasa D, Fuller H, Hall R, et al. A comparison of sucralfate and ranitidine for the prevention of upper gastrointestinal bleeding in patients requiring mechanical ventilation. Canadian Critical Care Trials Group. N Engl J Med 1998;338:791-7.

11. Bouza E, Pérez MJ, Muñoz P, Rincón C, Barrio JM, Hortal J. Continuous aspiration of subglottic secretions in the prevention of ventilator-associated pneumonia in the postoperative period of major heart surgery. Chest 2008;134:938-46.

12. Torres A, Gatell JM, Aznar E, el-Ebiary M, Puig de la Bellacasa J, González J, et al. Re-intubation increases the risk of nosocomial pneumonia in patients needing mechanical ventilation. Am J Respir Crit Care Med 1995;152:137-41.

13. Berra L, De Marchi L, Panigada M, Yu ZX, Baccarelli A, Kolobow T. Evaluation of continuous aspiration of subglottic secretion in an in vivo study. Crit Care Med 2004;32:2071-8.

14. Ramirez P, Ferrer M, Torres A. Prevention measures for ventilator-associated pneumonia: A new focus on the endotracheal tube. Curr Opin Infect Dis 2007;20:190-7.

15. Ranjan N, Chaudhary U, Chaudhry D, Ranjan KP. Ventilator-associated pneumonia in a tertiary care Intensive Care Unit: Analysis of incidence, risk factors and mortality. Indian J Crit Care Med 2014;18:200-4.

16. Golia S, Sangeetha KT, Vasudha CL. Microbial profile of early and late onset ventilator associated pneumonia in the Intensive Care Unit of a tertiary care hospital in Bangalore, India. J Clin Diagn Res 2013;7:2462-6.

17. Bonten MJ, Kollef MH, Hall JB. Risk factors for ventilator-associated pneumonia: From epidemiology to patient management. Clin Infect Dis 2004;38:1141-9.

18. Jaimes F, De La Rosa G, Gómez E, Múnera P, Ramírez J, Castrillón S. Incidence and risk factors for ventilator-associated pneumonia in a developing country: Where is the difference? Respir Med 2007;101:762-7.

19. Huang KT, Tseng CC, Fang WF, Lin MC. An early predictor of the outcome of patients with ventilator-associated pneumonia. Chang Gung Med J 2010;33:274-82.

20. Yang CS, Qiu HB, Zhu YP, Huang YZ, Xu XT, Gao L. Effect of continuous aspiration of subglottic secretions on the prevention of ventilator-associated pneumonia in mechanically ventilated patients: A prospective, randomized, controlled clinical trial. Zhonghua Nei Ke Za Zhi 2008;47:625-9.

21. Alsaddique AA. Use of continuous subglottic suction in established ventilator associated pneumonia. Saudi J Anaesth 2009;3:20-4.

22. Safdar N, Crnich CJ, Maki DG. The pathogenesis of ventilator-associated pneumonia: Its relevance to developing effective strategies for prevention. Respir Care 2005;50:725-39. 